\title{
Intervención en Dinámicas Familiares Fuera del Domicilio en Personas con TEA
}

\section{Family Intervention Out Home in People with Autism}

\author{
Beatriz López, Berta Fraga, Leticia Sambade
}

\author{
Asociación DISMACOR
}

\begin{abstract}
Resumo
Traballar en contornas naturais é beneficioso para as persoas con TEA, especialmente para propiciar a xeneralización tanto de ambientes, de persoas, de estímulos, de respostas e de habilidades, así como o uso funcional destas. Neste traballo realízase unha avaliación inicial dun suxeito con TEA pasando posteriormente a efectuar unha intervención baseada na modificación das dinámicas familiares fora dos domicilios. Finalmente realízase unha avaliación final na que se constatan os cambios percibidos. Os resultados informan de que este tipo de intervencións provocan grandes avances nos suxeitos proporcionándolles ferramentas útiles e significativas facilmente xeralizables ás dinámicas da vida cotiá.

Palabras clave: Trastornos de Espectro Autista, contornas naturais, familia, inclusión, normalización.
\end{abstract}

\begin{abstract}
People with disabilities and those who have autism, have important difficulties to set appropriate interactions, which let them to have good relationships. In these lines a new way of intervention is shown, which is based on the creation of groups of people with similar characteristics in which social skills are practiced and which is thought to form a support group that would improve social and personal development.

Keywords: social skills, support groups, social development, autism.
\end{abstract}

\section{Introdución}

Os trastornos do Espectro do Autismo constituen un grupo de condicións de límites difusos e cambiantes caracterizados pola presencia de dificultades clínicamente significativas na interacción social e na comunicación, e polas conductas e intereses restrinxidos e estereotipados, que resultan evidentes xa nos tres primeiros anos de vida (Bellinchón, 2010).

Martos (2005) sinala que o autismo vai implicar sempre unha alteración, maior ou menor, de doce aspectos do desenvolvemento: as destrezas de relación, acción e atención conxunta, teoría da mente, comunicación, linguaxe expresiva e receptiva, anticipación, flexibilidade, asignación de sentido á acción, imaxinación, imitación e suspensión.

En todos os casos de autismo atópanse alteracións pragmáticas e comunicativas, que se materializan en déficits para a correcta adquisición dos compoñentes estruturais ou gramaticais, problemas no desenvolvemento da comunicación intencional e conversacional e alteracións na comprensión referencial que permite comprender o que sinte e quere dicir a outra persoa (Sixto, J, e Belinchón, M., 1997). Estes déficits na comunicación social pódense explicar de acordo a varias teorías que se postularon para explicar o funcionamento das persoas con autismo: Teoría da Mente, segundo a cal as persoas con autismo manifestan problemas para atribuír os estados mentais para explicar tanto o propio comportamento como o dos que lle rodean (TirapuUstárroz, J., Pérez-Sayes, G., Erekatxo-Bilbao, M. e Pelegrín-Valero, C., 2007). Teoría da Coherencia Central, que explica a incapacidade dos autistas para procesar a información que se lles mostra atendendo soamente aos detalles e non sendo quen de contextualizala nun referente máis amplo (Frith, U., 2003) e a Teoría Emocional que considera que existe un déficit intersubxectivo nas persoas con autismo (Buceta, 2011) que lles dificulta a capacidade innata de relacionarse con outros e, polo tanto, de aprender a identificar os seus estados emocionais.

Martos (2005) indica que o tratamento nos TEA é, en esencia, un intento de desenvolver no neno ou no adulto as funcións alteradas, e diminuír as anomalías emocionais ou de conduta de que pode acompañarse o seu trastorno. Aínda que as persoas con trastornos de espectro autista non poidan constituír as funcións mencionadas polas vías habituais de desenvolvemento, que permiten a súa adquisición por procesos de interacción natural e aprendizaxe implícita, poden desenvolver aspectos delas (en maior ou menor grao, dependendo do seu trastorno) a través de procesos de ensino explícito.

Segundo López-Gómez et al. (2011), os compoñentes básicos que se deberían ter en conta no deseño dunha intervención para persoas con trastorno de espectro autista deberían contemplar polo menos:

a. O desenvolvemento, aprendizaxe e motivación cara ao acto comunicativo na interacción social e no contexto próximo.

b. A aprendizaxe de respostas ao medio e ás súas demandas estimulares.

c. A adecuación do programa de intervención ao grao de afectación e ás súas características de desenvolvemento.

d. Definición de obxectivos que impliquen o desenvolvemento das habilidades necesarias para a vida cotiá. 
Ademais posiblemente, o compoñente máis importante sexa a familia, pero esta só actuará de forma coherente e adecuada se detrás existe un grupo de profesionais que maximice as características e posibilidades dos propios pais e nais.

$\mathrm{Na}$ actualidade non hai tratamentos curativos $\mathrm{e}$ únicamente se conta con ferramentas de intervención paliativa e psicoeducativa. En canto aos desacordos, existe unha gran polémica sobre cal é o tratamento máis eficaz, desacordo que se traduciu nunha certa confusión para os pais e achegados (Bowker et al., 2011) e conflito para os profesionais, xestores e políticos que deben participar na toma de decisións respecto ao tratamento. Por todo elo, hoxe en día o tratamento dos TEA tende a ser personalizado, empregando técnicas adaptadas a cada persoa.

No presente estudo preténdese expoñer un caso dun suxeito con TEA empregando técnicas nas contornas naturais e apoiadas pola familia. A hipótese principal é que este tipo de programas melloran o desenvolvemento dos suxeitos con estas características.

\section{Método}

\section{Participantes}

Selecciónase un suxeito varón de 8 anos diagnosticado inicialmente cun trastorno de espectro autista de nivel 2 (DSMV, 2013). Pertence a unha familia de nivel sociocultural medio residente nunha zona rural preto dunha urbe de 225.000 habitantes.

A unidade familia componse dos pais, unha irmá de 5 anos e o rapaz, o cal se atopa escolarizado en $4^{\circ}$ de Primaria nun centro ordinario onde recibe 2 horas semanais de pedagoxía terapéutica e unha de audición e linguaxe.

O suxeito conta cunha linguaxe propia da súa idade cronolóxica, pero o profesorado refire grandes alteracións á hora de establecer relacións sociais: presenta dificultades na utilización do contacto ocular como mecanismo regulador das interaccións sociais, non reacciona adecuadamente ás emocións, as respostas sociais son bastas e bruscas en moitas ocasións, non comprende os dobres sentidos nin os chistes, cústalle iniciar interaccións correctamente... Porén é capaz de saudar e despedirse se se lle pide, pero en poucas ocasións realízao dunha maneira automatizada. Participa no xogo sobre todo se llo propón o adulto tendo preferencia por aqueles de tipo motor como por exemplo o futbol.

En relación á área comportamental presenta gran número de rabietas violentas e desproporcionadas sobre todo en instantes de tensións, situacións pouco previsibles... é neses momentos cando se producen berros, golpes, movementos bruscos, carreiras sen sentido, ataques de ira... os cales resulta difíciles de controlar.

Mostra condutas estereotipadas (acenos, xiros e movementos repetitivos) e unha gran inflexibilidad conductual con resistencia ante os cambios, apego aos obxectos e rutinas. En ocasións presenta un comportamento "desafiante" e escasa capacidade de autocontrol.

\section{Instrumentos}

Para a avaliación inicial e final empréganse unhas follas de recollida de información observacional e rexistros de información extraidos das entrevistas coa familia e profesionais que interveñen co suxeito.

Así mesmo emprégase un programa de intervención na contorna natural fora do domicilio que conta cos seguintes obxectivos:

a. Favorecer un desenvolvemento social e comunicativo.

b. Ensinar competencias adaptativas, adestrando as funcións cognitivas e emocionais. c. Tratar os problemas de conduta e emocionais asociados que interfiren no seu desenvolvemento.

d. Prestar apoio e dar información ás familias e profesionais implicados.

e. Buscar metas para a intervención realistas, considerando a curto, medio e longo prazo.

Este programa efectuase en diferentes lugares abertos e pechados nos que é dificil preveer algúns aspectos, polo que o suxeito debe adaptarse progresivamente a esta situación de incertidume. Para elo empréganse pictogramas e diarios de sesión nos que se describen diferentes esceas. Posteriormente estos apoios irán desvanecéndose a medida que o suxeito se adapta aos cambios.

\section{Procedimiento}

Procédese a realizar unha avaliación inicial e final cualitativa na que se recolle a través da observación e entrevistas coa familia e profesorado aquelas dificultades comportamentais mais salientables para así poder realizar unha intervención adaptada ás necesidades reais de cada intre.

O proceso de intervención efectuase cun programa de 2 horas de atención semanal ao longo de 2 anos. Realízase unha coordinación coa familia e centro educativo consensuando obxectivos de traballo e establecendo pautas para diminuir aquelas situacións problemáticas.

Todo elo realízase en contornas naturais nas que se desenvolve o suxeito apoiando os cambios e diminuindo progresivamente as dificultades. Para elo o programa emprega aproximacións sucesivas a situacións que xeran estrés, diminuense as rutinas adaptándose ao ritmo do suxeito, adiantando as situacións cambiantes e introduccindo variacións paulatinamente en cada un dos eidos a traballar...

\section{Resultados}

A continuación, nas Táboas 1 e 2 recollerase a evolución antes e despois do programa de intervención. 
Táboa 1.

Evolución no desenvolvemento antes e despois da intervención. Lugares abertos

\begin{tabular}{|c|c|c|}
\hline Situación & Pretest & Postest \\
\hline No parque & $\begin{array}{c}\text { Presenta problemas } \\
\text { para achegarse a } \\
\text { persoas da súa mesma } \\
\text { idade mostrando } \\
\text { dificultades de contacto } \\
\text { visual, expresións } \\
\text { inaxeitadas ou xeitos } \\
\text { desadaptativos. } \\
\text { Non inicia os xogos. } \\
\text { As veces fuxe da } \\
\text { situación mostrando } \\
\text { estereotipias. }\end{array}$ & $\begin{array}{c}\text { Achegase aos } \\
\text { rapaces da súa } \\
\text { idade cun mellor } \\
\text { contacto visual e } \\
\text { expresións } \\
\text { adaptadas. } \\
\text { Ainda lle custa } \\
\text { iniciar os xogos, } \\
\text { pero é quen de } \\
\text { unirse a un grupo } \\
\text { que está a xogar. } \\
\text { Xa non fuxe das } \\
\text { situacións de xogo } \\
\text { e non se observan } \\
\text { estereotipias. }\end{array}$ \\
\hline No autobús & $\begin{array}{c}\text { Mostra reaccións } \\
\text { desadaptativas ao subir, } \\
\text { pagar o billete e incluso } \\
\text { ao sentarse e } \\
\text { permanecer nun lugar } \\
\text { durante o traxecto. }\end{array}$ & $\begin{array}{l}\text { É quen de subir ao } \\
\text { autobús, pagar ao } \\
\text { conductor, manter } \\
\text { unha conducta } \\
\text { adaptativa e baixar } \\
\text { adecuadamente. }\end{array}$ \\
\hline $\begin{array}{l}\text { Na cancha de } \\
\text { fútbol e } \\
\text { baloncesto }\end{array}$ & $\begin{array}{l}\text { Non quere iniciar o } \\
\text { xogo nin unirse a él. } \\
\text { Tende a xogar en } \\
\text { solitario. }\end{array}$ & $\begin{array}{c}\text { É quen de unirse } \\
\text { ao grupo que está } \\
\text { xogando e } \\
\text { desfrutar da } \\
\text { situación. }\end{array}$ \\
\hline $\begin{array}{l}\text { Saída con } \\
\text { amigos } \\
\text { (minigolf, } \\
\text { bolera...) }\end{array}$ & $\begin{array}{l}\text { Non hai amizades reais. } \\
\text { Fuxe doutros rapaces e } \\
\text { non desexa relacionarse } \\
\text { con eles. }\end{array}$ & $\begin{array}{c}\text { Establece vínculos } \\
\text { con persoas da súa } \\
\text { idade en diferentes } \\
\text { situacións. } \\
\text { Intercambia os } \\
\text { teléfonos con eles } \\
\text { e cítanse para } \\
\text { verse en diversos } \\
\text { lugares sendo } \\
\text { intercambios } \\
\text { socialmente } \\
\text { satisfactorios. }\end{array}$ \\
\hline $\begin{array}{l}\text { Xogar coa } \\
\text { irmá }\end{array}$ & $\begin{array}{l}\text { Cústalle interaccionar } \\
\text { coa súa irmá. Non } \\
\text { teñen xogos en común } \\
\text { sendo o habitual que } \\
\text { pelexen por algún } \\
\text { obxecto remantando } \\
\text { con enfados e choros. }\end{array}$ & $\begin{array}{l}\text { Aprendense algúns } \\
\text { xogos que poden } \\
\text { compartir a pesar } \\
\text { da diferencia de } \\
\text { idade. A relación } \\
\text { mellora e son quen } \\
\text { de pasar algún } \\
\text { tempo de calidade } \\
\text { dun modo } \\
\text { conxunto. }\end{array}$ \\
\hline
\end{tabular}

Táboa 2.

Evolución no desenvolvemento antes e despois da intervención. Lugares pechados.

\begin{tabular}{lcc}
\hline Situación & Pretest & Postest \\
\hline & Os monitores refiren & Xa participa nos \\
& que non quere xogar & $\begin{array}{c}\text { xogos en grupo } \\
\text { nun }\end{array}$ \\
no grupo dos nenos. O & desfrutando deles. \\
campamento & suxeito permanece & Desaparecen os \\
& aillado xogando de & desprazamentos \\
& maneira individual, & circulares e \\
desplazándose en & estereotipias.
\end{tabular}

\begin{tabular}{|c|c|c|}
\hline & $\begin{array}{l}\text { círculos e mostrando } \\
\text { estereotipias. }\end{array}$ & \\
\hline Nun restaurante & $\begin{array}{l}\text { Mostra rexeitamento a } \\
\text { probar novos } \\
\text { alimentos. } \\
\text { Non é capaz de seguir } \\
\text { unhas normas de } \\
\text { cortesía para saúdar, } \\
\text { pedir os pratos, } \\
\text { solicitar a conta... } \\
\text { Existen } \\
\text { comportamentos } \\
\text { desadaptativos á hora } \\
\text { de comer (masticar } \\
\text { coa boca aberta, non } \\
\text { usar servilleta, } \\
\text { manchar todo...) }\end{array}$ & $\begin{array}{l}\text { Diminuen algúns } \\
\text { rexeitamentos a } \\
\text { alimentos. } \\
\text { Segue unhas } \\
\text { normas de cortesía } \\
\text { axeitadas. } \\
\text { Mellórase nos } \\
\text { comportamentos } \\
\text { adaptativos á hora } \\
\text { de comer. }\end{array}$ \\
\hline $\begin{array}{l}\text { Nunha } \\
\text { exposición }\end{array}$ & $\begin{array}{l}\text { Xeralmente non quere } \\
\text { ir e mostra berrinches } \\
\text { para evitar entrar ou } \\
\text { permanecer nela. }\end{array}$ & $\begin{array}{l}\text { Acepta acudir e } \\
\text { permañece no } \\
\text { grupo aínda que } \\
\text { non lle agrade. } \\
\text { Tolera mellor a } \\
\text { situación. } \\
\end{array}$ \\
\hline $\begin{array}{l}\text { Festas } \\
\text { (Antroido, } \\
\text { Nadal...) }\end{array}$ & $\begin{array}{l}\text { Négase a ir a festas } \\
\text { manifestando estrés e } \\
\text { inquietude motora no } \\
\text { caso de que se lle } \\
\text { convide. } \\
\text { Non quere disfrazarse } \\
\text { nin participar en } \\
\text { celebracións da } \\
\text { escola. }\end{array}$ & $\begin{array}{l}\text { Pídelle á familia } \\
\text { poder asistir a } \\
\text { unha festa de } \\
\text { Antroido e deixa } \\
\text { que lle pinten a } \\
\text { cara ainda que } \\
\text { segue rexeitando } \\
\text { os disfraces. }\end{array}$ \\
\hline $\begin{array}{l}\text { Supermercado/ } \\
\text { compras }\end{array}$ & $\begin{array}{c}\text { Non quere ir de } \\
\text { compras de ningún } \\
\text { tipo. A familia refire } \\
\text { que lle resulta moi } \\
\text { complicado } \\
\text { introducilo nesta } \\
\text { dinámica sendo moi } \\
\text { difícil levalo a mercar } \\
\text { roupa. }\end{array}$ & $\begin{array}{c}\text { Acepta ir a } \\
\text { comprar alimentos } \\
\text { para despois } \\
\text { preparar el as } \\
\text { receitas na súa } \\
\text { casa. } \\
\text { Acepta de bo } \\
\text { agrado mercar a } \\
\text { súa roupa ainda } \\
\text { que o proceso debe } \\
\text { ser rápido. }\end{array}$ \\
\hline Cociña & $\begin{array}{l}\text { Rexeita os traballos de } \\
\text { tipo manual, tocar } \\
\text { texturas novas, a } \\
\text { suciedade, as tarefas } \\
\text { de limpeza da } \\
\text { cociña... }\end{array}$ & $\begin{array}{c}\text { Tras preparar } \\
\text { varias receitas do } \\
\text { seu agrado é quen } \\
\text { de manipular, } \\
\text { limpar e realizar } \\
\text { diferentes tarefas } \\
\text { dentro da cociña. }\end{array}$ \\
\hline
\end{tabular}

\section{Discusión}

As intervencións realizadas en contornas naturais caracterízanse polo feito de que se efectuan nos lugares habituais nos que o suxeito vive e desenvólvese no día a día, como son o fogar e a comunidade. Este tipo de intervencións prestan atención non só ao espazo onde se desenvolven as persoas senón tamén á contorna social coidadores habituais do neno/a como os pais, a familia, mestres... Por tanto, non se trata de realizar na casa ou na comunidade a intervención que se pode facer nunha clínica, senón que se vai traballar conxuntamente para formar ás persoas que viven o día a día co suxeito. 
No caso exposto, tanto a familia como os profesionais constatan importantes cambios fundamentalmente a nivel condutual. Destácanse por exemplo:

- Diminución das obsesións e comportamentos estereotipados. Desaparecen as carreiras en círculos, aleteos... O suxeito pasa a expresar o seu malestar a través da linguaxe oral e canaliza emocións mediante diferentes técnicas así coma o deporte.

- Unha importante mellora nas relacións sociais. Diminuen os comentarios ferintes cara os demais e increméntanse as expresións positivas de agrado en diferentes situacións. A familia refire que o rapaz comeza a ter algúns amigos e establece relacións con eles de calidade con intercambios asertivos.

- Redúcese o apego ás rutinas e resistencia aos cambios. A familia destaca que xa non vive centrado no reloxo e chegar á hora exacta. Increméntase a flexibilidade e tolera con maior agrado que se varien as actividades da súa axenda.

Este tipo de avances permiten que se acepte a hipótese de que este tipo de intervencións melloran o desenvolvemento e calidade de vida das persoas con trastorno de espectro autista. Aínda que os tratamentos deben ser personalizados e adaptados a cada situación é posible acadar importantes cambios.

\section{Referencias}

American Psichiatric Association (2013). Diagnostic and Statistical Manual of Mental Disorders. DSMV.

Bellínchón, M. (2010) Investigaciones sobre autismo en español: problemas y perspectivas. Madrid: Paradox.

Bowker, A. et al. (2011). Treatments for Autism: Parental choices and perceptions of change. Journal of Autism and Developmental Disorders, 41, 1373-1382.

Buceta, M.J. (2011). Manual de Atención Temprana. Madrid: Editorial Síntesis S.A.

Frith, U. (2003). Autism: Explaining the Enigma. Oxford: Blackwell Publishing.

López-Gómez, S., Rivas, R. M. e Taboada, E. M. (2011). El papel de la intervención psicoeducativa en la sintomatología del trastorno autista. Apuntes de Psicología, 28, 145-159.

Martos, J. (2005). Intervención educativa en autismo desde una perspectiva psicológica. Revista de Neurología, 40, 177-180.

Sixto, J. e Belinchón, M. (1997). Ineficacia en la Comunicación Referencial de Personas con Autismo y otros Trastornos relacionados: un Estudio Empírico. Anuario de Psicología, 75.

Tirapu-Ustárroz, J., Pérez-Sayes, G., Erekatxo-Bilbao, M. e Pelegrín-Valero, C. (2007). ¿Qué es la Teoría de la Mente? Neurol, 44 (8). 